\title{
Androgen Receptor Signaling in Prostate Cancer: New Twists for an Old Pathway
}

\author{
Junjie Feng ${ }^{1,2}$, S Lilly Zheng ${ }^{1,2}$, Wennuan Liu ${ }^{1,2}$, William B. Isaacs ${ }^{3}$ and Jianfeng $\mathrm{Xu}^{1,2,4 *}$
}

${ }^{1}$ Center for Cancer Genomics, Wake Forest School of Medicine, Winston-Salem, NC, USA

${ }^{2}$ Center for Genomics and Personalized Medicine Research, Wake Forest School of Medicine, Winston-Salem, NC, USA

${ }^{3}$ Department of Urology, Johns Hopkins Medical Institutions, Baltimore, MD, USA

${ }^{4}$ Van Andel Research Institute, Grand Rapids, MI, USA

\begin{abstract}
Secretory leukocyte protease inhibitor is a multifunctional protein with a variety of activities attributed to it. A significant increase in the expression of Secretory leukocyte protease inhibitor was noticed in syncytiotrophoblasts following differentiation of cytotrophoblasts in to syncytiotrophoblasts by addition of Forskolin. Using the BeWo cells which are derived from choriocarcinoma, the effect of addition of progesterone and estradiol on the expression of Secretory leukocyte protease inhibitor by Reverse Transcription Polymerase Chain Reaction was assessed. It was found that while addition of low concentration of progesterone resulted in a significant increase in expression of Secretory leukocyte protease inhibitor, addition of estradiol even at high concentration had no effect. The specificity of effect of progesterone was established by the observation that addition of Progesterone along with progesterone receptor antagonist (RU484) resulted in decrease in the level of expression of Secretory leukocyte protease inhibitor. These results suggest that Secretory protease leukocyte protease inhibitor is a progesterone regulated gene.
\end{abstract}

Keywords: Androgen Receptor, Prostate Cancer, GWAS, SNPs, Cistrome, Fusion Gene

\begin{abstract}
Abbreviations: AR: Androgen Receptor; PCa: Prostate Cancer; ADT: Androgen Deprivation Therapy; CRPC: Castration Resistant PCa; LHRH: Luteinizing-Hormone-Releasing Hormone; LH: Luteinizing Hormone; DHT: Dihydrotestosterone; HSP: Heat Shock Protein; ARE: Androgen-Responsive Element; ChIP-on-chip: Chromatin immunoprecipitation coupled with tiled oligonucleotide microarrays; ChIP-Seq: Chromatin immunoprecipitation coupled with massively parallel sequencing; ADPC: Androgen-Dependent Prostate Cancer cell line; AIPC: Androgen-Independent Prostate Cancer cell line; GWAS: Genome-Wide Association Study; SNP: Single Nucleotide Polymorphism; DSB: DNA Double-Stranded Breaks; AID: ActivationInduced Cytidinedeaminase; TOP2B: Topoisomerase II beta; HGPIN: High-Grade Prostatic Intraepithelial Neoplasia
\end{abstract}

\section{Introduction}

The critical role of androgenic hormones in prostate cancer $(\mathrm{PCa})$ has been well-recognized for almost seventy years, ever since Huggins and Hodges first reported the significant clinical effects of suppressing serum androgen levels in men with advanced PCa in 1941[1]. Today, clinical intervention for this one of the most common and deadly cancers [2] still capitalizes on this early appreciation and the mechanistic understanding of how androgens are synthesized and function through the signaling pathway anchored on the androgen receptor (AR). The therapeutic regimens to suppress testicular androgen production (surgical or medical castration, termed "androgen deprivation therapies", or ADTs), alone or in combination with antiandrogens that block AR activity, still remain the mainstay of treatment of locally advanced or metastatic PCa.

Yet patients receiving these androgen-AR axis targeting treatments, despite initial beneficial responses, almost invariably relapse with a more aggressive and typically deadly form of PCa that has been termed castration resistant PCa (CRPC). Although it is possible that CRPC may arise as a consequence of selection pressure imposed by ADTs that favours the growth of androgen-insensitive cells $[3,4]$, recent evidence indicates that growth of the vast majority of cancer cells in tumors relapsing from castration still depend heavily on the AR signaling axis [5-11], in an adaptation process called "AR reactivation" that involves a variety of mechanisms (reviewed in ref [12-14]). Based on this understanding, multiple novel AR signaling-targeting reagents for CRPC have been under active trial or development, some of which have shown promising clinical effects (reviewed in ref [13,15-17]).

The past five years have seen several new advances in the field, which have greatly invigorated our views about this seemingly old pathological pathway. As these new findings demonstrate, the scope of and the extent to which the androgen-AR axis contributes to the pathogenesis and progression of PCa may be significantly underestimated. This minireview intends to summarize these new advances, and discuss their potential significance in the basic, translational and clinical research in PCa.

\section{AR Signaling: Established Knowledge}

Androgens are a class of steroid hormones that control the development and maintenance of male characteristics [18] Testosterone represents the most abundant androgenic hormone that is primarily synthesized in and secreted from testis under the endocrine control of the luteinizing-hormone-releasing hormone (LHRH)luteinizing hormone (LH) axis [19]. Within prostate, circulating testosterone is converted irreversibly into a more potent androgen dihydrotestosterone(DHT), through the activities of $5 a$-reductases (SRD5A1 and SRD5A2) [20,21].

${ }^{*}$ Corresponding author: Dr. Jianfeng Xu, Center for Cancer Genomics, Medica Center Blvd, Winston-Salem, NC 27157, Tel: (336) 713-7500; Fax: (336) 713-7566; E-mail: jxu@wfubmc.edu

Received August 15, 2011; Accepted September 22, 2011; Published September 29, 2011

Citation: Feng J, Zheng SL, Liu W, Isaacs WB, Xu J (2011) Androgen Receptor Signaling in Prostate Cancer: New Twists for an Old Pathway. J Steroids Hormon Sci S2:001. doi:10.4172/2157-7536.S2-001

Copyright: (c) 2011 Feng J, et al. This is an open-access article distributed unde the terms of the Creative Commons Attribution License, which permits unrestricted use, distribution, and reproduction in any medium, provided the original author and source are credited. 
The effects of androgens are mediated by androgen receptor (AR), a ligand-dependent transcription factor and member of nuclear receptor superfamily $[22,23]$. In the absence of androgen binding, $\mathrm{AR}$ is held inactive in cytoplasm by association with inhibitory chaperone proteins such as heat shock proteins (HSPs)[24,25]. Binding of testosterone, or more potently of DHT, causes a dramatic conformational change of AR that releases it from inhibitory HSPs and induces its homodimerization, post-translational modification, nuclear translocation, and association to specific DNA sequences termed "androgen-responsive elements (AREs)" [26-28]. The AREs-bound AR homodimers then serve as a platform to recruit basal transcriptional machinery and other transcriptional co-regulators (coactivators and corepressors) to initiate or modulate the transcriptional program of androgen-responsive genes [27,29-31]. Expression of these AR target genes combinatorially determines a variety of phenotypes including differentiation, proliferation, survival, apoptosis, and metastasis [3237]. In prostate, the intact androgen-AR signaling axis is required for the development and maintenance of normal prostatic tissues [38]. It is notable that the dependence of prostate cells on AR signaling persists after neoplastic transformation, which essentially underlies the androgen-driven hypothesis to explain the oncogenesis and progression of $\mathrm{PCa}$, and forms the basis of all AR blocking therapies.

The detailed mechanistic understanding of how androgens are synthesized and functioned through AR signaling has facilitated development of various strategies for targeted interference of the androgen-AR signaling axis to manage PCa. Some of the treatments aim at the LHRH-LH-testosterone axis to cut or reduce androgen supplies to prostate tumors, which include surgical castration (orchiectomy, for removal of testosterone-producing testes), LHRH antagonists (e.g. Abarelix and Degarelix, for direct inhibition of LHRH receptors), and LHRH agonists (e.g. leuprolide, goserelin and histrelin, for downregulation of LHRH receptors). Others (e.g. flutamide, bicalutamide, and nilutamide) compete with testosterone and DHT for binding with AR are thus termed "antiandrogens". These various androgen-AR targeting regimens have proved to be effective, causing tumor remission, symptomic palliation, and improved patient survival. For example, ADT typically results in $>90 \%$ reduction of serum androgens [39], leading to improved survival in high-risk localized disease and $80-90 \%$ response rate in patients with metastatic PCa [40].

However, as mentioned above, $\mathrm{PC}$ a patients receiving ADTs almost always end up developing CRPCs, in an adaptive process that reactivates AR signaling. A variety of mechanisms have been implicated in this process, among which include: 1) increased expression or activity of AR, by AR amplification, overexpression, gain-of-function mutations, or alternative splicing; 2) increased AR signaling, by aberrant posttranslational modifications of $\mathrm{AR}$, deregulation of $\mathrm{AR}$ coactivators, or loss of AR corepressors; 3) increased intra-tumor androgen synthesis to increase androgen levels in CRPC tumors, mediated primarily by overexpression of enzymes involved in the steroid biosynthesis (reviewed in ref [12-14,41]). Several novel CRPC-targeting drugs under development are based on these mechanistic understanding. Abiraterone acetate $\left(\right.$ ZYTIGA $\left.^{\mathrm{TM}}\right)$, a specifc inhibitor for CYP17A1 that blocks the intra-tumor and extragonadal synthesis of testosterone, was shown to cause beneficial responses in CRPC patients [42] and has been approved to treat CRPC patients receiving prior docetaxel chemotherapy in combination with prednisone. Several other new AR signaling-targeting reagents, such as the AR antagonists MDV-3100 [42] and BMS-641988 [43] and the androgen biosynthesis inhibitors TAK-700 [44] and VN/124-1 [45], have also shown promising effects and are under clinical trials.
Due to these successes in our mechanistic understanding of AR signaling and in our utilization of this knowledge in the management of $\mathrm{PCa}$, current consensus goes that $\mathrm{AR}$ signaling plays a pivotal role in the oncogenesis and progression of PCa. Significant gaps and challenges, however, still remain to be resolved. First, although the androgen-driven hypothesis is tantalizing in explanation of the PCa etiology and progression, the epidemiological evidence for it has remained conflicting for many studies and less convincing for others. Second, great inter-individual variations are frequently observed among men in their susceptibility for $\mathrm{PCa}$, their pathological progression into metastatic diseases, and their responses to the aforementioned AR blocking therapies, which are yet to be sufficiently explained. Third, almost all of the AR blocking therapies ultimately fail, leaving the question wide open as what molecular mechanisms account for these failures. These gaps are arguably all attributable to our underappreciation of the complexity of PCa and our far from sufficient knowledge of the genetic and molecular details delineating the AR signaling pathway.

\section{AR Signaling: New Advances in the Mechanistic Study}

Recently by combining chromatin immunoprecipitation with tiled oligonucleotide microarrays (ChIP-on-chip) or with massively parallel sequencing (ChIP-Seq), the genome-wide AR binding sites (termed "AR cistrome") have been identified from a variety of PCa cell lines in multiple independent studies [46-50]. It was found that contrary to our expectation, most of the experimentally defined AR binding sites contain noncanonical AREs that are shown to be functional. One of these noncanonical ARE, located $\sim 13.5 \mathrm{~kb}$ upstream of androgenresponsive TMPRSS2 gene, was demonstrated to be a functional enhancer participating in transcriptional regulation of TMPRSS2 and TMPRSS2-ETS fusion genes[46]. Furthermore, the majority of the AR binding sites were found to be located far $(>10 \mathrm{~kb})$ from any androgenregulated genes $[46,50]$, and are frequently found to contain acetylated histones $\mathrm{H} 3 / \mathrm{H} 4$, PolII and p160 coactivators [46,50], in consistency of their role as functional enhancers.

By comparing the androgen-dependent cell line (ADPC) and its androgen-independent derivative (AIPC), generated after prolonged androgen deprivation, considerable differences in the AR cistromes as well as the AR-controlled transcriptional programs were observed [47] One difference is in the M-phase cell cycle genes. Enhancers of these genes were found to have greater AR occupancy in AIPC cells than in ADPC cells in the presence of androgen, with high expression of these genes seen in the former correspondingly. Thus by investigating this CRPC-mimicking cell line model, this study suggests that AR may regulate a distinct transcription program in CRPC cells than in ADPC cells, which may account for their distinctive phenotypes such as androgen-independent cell proliferation.

Another noteworthy discovery is that co-occupancy of AR with other transcription factors, such as FOXA1, TEF1, PU1, GATA2 and OCT1 $[46,49]$, was frequently found in AR-binding sites, suggesting that AR may be working in collaboration with other transcription factors to control the expression of androgen-responsive genes. In support of this view, FOXA1, the DNA-binding transcription factor that contains chromatin-remodeling activity, has been found to serve as a pioneer factor binding to the FKH motif that is often concurrent with the AREs (> 60\% concurrent rate in PCa cells at the basal state[51]), opening the compacted chromatin, and allowing subsequent association of AR at the AREs within these enhancers to cooperatively regulate target gene expression. The initial binding of FOXA1 to chromatin is found to be dependent on $\mathrm{H} 3 \mathrm{~K} 4 \mathrm{me} 1 / \mathrm{me} 2$ distribution in a cell lineage- 
specific manner [47,51]. The critical role of FOXA1 in AR signaling is further confirmed by the observation that FOXA1 knockdown triggers dramatic reprogramming of the hormonal response by causing a massive switch in AR binding to a distinct cohort of pre-established enhancers [52]. As another supportive example, ERG, a transcription factor of the ETS family that is not expressed in normal prostate epithelium but is highly expressed in PCa cells as a result of TMPRSS2$E R G$ gene fusion, has been found to bind with and suppress AR. Because there is an extraordinary degree ( $>40 \%$ ) of overlap between AR and ERG binding sites in TMPRSS2-ERG fusion-positive PCa cells, it is speculated that ERG may play a crucial role in PCa progression of these fusion-positive tumors by disrupting AR signaling in favor of a dedifferentiation program induced by EZH2, an $E R G$ target [48].

Based on these new findings, it is evident that AR signaling is more complex than we previously thought. As demonstrated in these PCa cell line models, AR signaling pathway may involve thousands of enhancers and possibly more target genes genome-wide, and may be dynamically regulated by both epigenetic factors and other collaborating protein factors, whose context-dependent interplay may determine the various cell-lineage-specific phenotypes. This growing knowledge of the molecular details of AR signaling pathway are expected to bring about significant impact on our understanding of the mechanisms by which altered AR signaling influences oncogenesis and progression of $\mathrm{PCa}$, and on our development of novel strategies for better management of the disease.

\section{AR Signaling in PCa Etiology: Emerging Evidence}

Given the central role of androgens in the development of normal prostate and the success of ADTs in the management of PCa, it has long been suggested that the AR signaling may be causally related to the etiology of PCa. Indirect evidences come from observations that men with deficiency in androgen synthesis, such as eunuchs or individuals with inactive $5 \alpha$-reductase $[53,54]$, and those with reduced or absent AR signaling, such as males with androgen insensitivity syndrome [55] or with spinal and bulbar muscular atrophy [56], do not develop $\mathrm{PCa}$, although the prostates in these men are largelyundeveloped. Furthermore, androgen administration has been demonstrated to induce or accelerate prostate cancer in some animal models $[57,58]$.

This androgen-driven hypothesis, however, has so far remained challenging to prove. In one attempt to correlate serum androgen levels with incidence of $\mathrm{PCa}$, several studies observed positive associations between elevated levels of serum androgens (testosterone, DHT, etc.) with occurrence of PCa [59-61], yet these associations failed to be confirmed in several other similar studies [62-66] and the subsequent meta-analyses [67,68]. In addition, several studies have reported an association between PCa susceptibility of the polymorphic CAG repeat in AR gene, which codes for a polyglutamine (PolyQ) tract in the N-terminal domain (exon 1 ) of the AR protein $[69,70]$. This association was nonetheless not supported by several large studies $[71,72]$. Conflicting results have also been reported for multiple genetic polymorphisms within genes participating in the androgen synthesis or AR signaling pathways. So far the only endogenous factors that have reached a consensus to be associated with increased PCa risk are increasing age, recent African ancestry, and family history[73].

Genome-wide association studies (GWAS) have been successfully applied in the reliable search for genetic variants associated with PCa. By the end of 2010, at least 33 PCa risk-associated single nucleotide polymorphisms (SNPs) had been identified by GWAS [74-85] and subsequently confirmed [86-89], thus most likely represent true genetic variants that influence the susceptibility of PCa. An overview of these 33 PCa risk-associated SNPs indicates that the majority of these PCa SNPs reside in non-coding genomic regions or within genes that are poorly characterized, leaving the molecular mechanism underlying these SNPs largely unknown. Recently by mapping these 33 established PCa risk loci to the AR cistrome identified by Wang et al. [47], our group found that they are significantly enriched in AR binding sites compared with other genomic regions [90]. Additionally, as many as one third (11 out of 33) of the PCa risk loci, containing these risk SNPs and the SNPs in linkage disequilibrium with them, are found to be overlapped with genomic regions containing AR-binding sites (Table 1), which notably include three PCa risk-associated SNPs at 8q24, a gene desert yet hot spot for multiple cancers. These bioinformatics analysis results were subsequently confirmed in our interrogation of genotyping data from two PCa GWAS populations [91], which showed that SNPs in the AR binding sites are more likely associated with PCa risk compared with SNPs across the genome. Although these studies provide only statistical evidence which still require experimental confirmation, they are in favor of the androgen etiology of PCa and suggest that altered AR signaling may underlie these genetic loci to confer PCa risk.

Two recent large clinical trials have lent a further support to the androgen-driven hypothesis. Reports show that administration of finasteride or dutasteride was able to cause $\sim 25 \%$ reduction of $\mathrm{PCa}$ risk compared with placebos [92,93], although at an unfortunate cost to increase the incidence of high-grade prostate cancers. These two reagents belong to a class of drugs termed $5 \alpha$-reductase inhibitors, which both block the prostatic conversion of testosterone into DHT and thus can inhibit the AR activity in prostate tissues. These findings thus strongly argue for AR signaling as a common and crucial mechanism underlying the PCa etiology and pathogenesis. However, there is still a long way to go as the evidence from these studies is at present only statistical, and more in-depth mechanistic approaches and understanding is urgently required.

\section{AR Signaling in PCa Oncogenesis: An Emerging Role of AR-Induced Gene Fusions}

Ever since Tomlins et al. made the seminal discovery that gene fusions between androgen regulated TMPRSS2 and ETS family transcription factors $E R G$ and $E T V 1$ were a frequent somatic alteration in PCa [94], intensive efforts have been invested to search for new fusion genes, investigate the underlying mechanism of their formation, and evaluate their specific roles in the pathogenesis of PCa.TMPRSS2-ERG/ ETV1 occur as a result of intra- or interchromosomal translocations, which create gene fusions between the 5'-untranslated region of

\begin{tabular}{|l|l|l|l|l|}
\hline SNPs & CHR & Position† & Regions & Known genes \\
\hline rs12621278 & 2 & $173,019,799$ & $2 q 31.1$ & ITGA6 \\
\hline rs17021918 & 4 & $95,781,900$ & $4 q 22.3$ & PDLIM5 \\
\hline rs10486567 & 7 & $27,943,088$ & $7 p 15$ & JAZF1 \\
\hline rs2928679 & 8 & $23,494,920$ & $8 p 21.2$ & NKX3.1 \\
\hline rs1512268 & 8 & $23,582,408$ & $8 p 21.2$ & NKX3.1 \\
\hline rs16901979 & 8 & $128,194,098$ & $8 q 24$ & \\
\hline rs620861 & 8 & $128,404,855$ & $8 q 24$ & \\
\hline rs1447295 & 8 & $128,554,220$ & $8 q 24$ & \\
\hline rs10993994 & 10 & $51,219,502$ & $10 q 11$ & MSMB \\
\hline rs1859962 & 17 & $66,620,348$ & $17 q 24.3$ & \\
\hline rs9623117 & 22 & $38,782,065$ & $22 q 13$ & TNRC6B \\
\hline
\end{tabular}

†Position is based on NCBI build 36

Table 1: GWAS-identified PCa risk-associated SNPs that reside within the ChIPon-chip defined AR binding sites. 
TMPRSS2 (21q22.2) and the 3'- coding regions of ERG (21q22.3) or ETV1 (7p21.2). ERG and ETV1 are normally not expressed in prostate epithelium ( $E R G$ is highly expressed in endothelial cells in the prostate), but the TMPRSS2-ERG/ETV1 fusion genes are overexpressed in PCa cells, mainly due to the acquired androgen-responsive promoter activity in the 5 ' promoters of the two fusion genes contributed byTMPRSS2 [94]. To date more than 10 similar fusion genes have been identified in $\mathrm{PCa}$, which involve different combination of 5 ' partners such as TMPRSS2, SLC45A3, KLK2, ACSL2, and 3' ETS partners including ERG, ETV1, ETV4 and ETV5 [95-100]. Among these, TMPRSS2-ERG represents the most frequent gene fusion events in $\mathrm{PCa}$, found in as many as 40-70\% PCa tumors [94,101-103]. All others comprise about $5 \%$ to $10 \%$ of all PCas [94-100]. It is also of note that besides TMPRSS2, many of these fusion genes' 5'-partners, including SLC45A3, KLK2, ACSL2, are demonstratively androgen-regulated genes. Thus one notable common feature shared by the majority of these fusion genes is androgen-regulated overexpression in PCa cells compared with normal prostatic epithelium.

Recently the molecular mechanism by which the two most frequent fusion genes TMPRSS2-ERG [104,105] and TMPRSS2-ETV1 [104] are formed has been identified, which notably requires the activity of AR. According to the proposed models, as a consequence of AR mediated gene activation, androgen-liganded AR first binds to the intronic regions of both translocation partners at presumable regulatory regions near the future breakpoints, which creates spatial proximity for the subsequent intra- and interchromosomal interaction. AR then triggers recombinogenic DNA double-stranded breaks (DSBs) at translocation loci by recruiting several genotoxic stress-induced enzymes such as activation-induced cytidine deaminase (AID), LINE-1 repeat-encoded ORF2 endonuclease, and/or topoisomerase II beta (TOP2B). Finally, the illegitimate repair of these AR-induced DSBs gives rise to the TMPRSS2-ERG/ETV1 rearrangements. Given that many other fusion genes also involve androgen-regulated genes (e.g. SLC45A3, KLK2, ACSL2) as the 5' partners, it seems a plausible hypothesis that AR is causally related to the formation of these fusion genes as well.

Accumulating evidence suggests that the recurrent AR-induced ETS rearrangements may play a crucial role in the tumorigenesis of PCa. It has been consistently demonstrated that the ETS gene fusions are present only in the neoplastic cells, but not in benign epithelial cells or stromal cells $[94,102,106]$. Additionally, the TMPRSS2-ERG fusion was observed in $\sim 20 \%$ of high-grade prostatic intraepithelial neoplasia (HGPIN) lesions [102,107], which were notably intermingled with PCa that carried the same fusion pattern. Yet no such fusion was seen in HGPINs geographically distant to $\mathrm{PCa}$, even if it was demonstrated in the PCa from the same individual [102], suggesting that the fusion-containing HGPINs may represent a subset of true neoplastic precursors for the fusion-positive PCa. Using in vitro and in vivo models recapitulating fusion-induced overexpression of ETS oncogenes, it was demonstrated that the ETV1or ERG overexpression confers neoplastic changes in benign prostate cells and induces epithelial hyperplasia and focal PINlesions in the mouse prostate [108-110]. However no malignant phenotypes, such as increase of cellular proliferation and anchorageindependent growth, were identified, suggesting that formation of the fusion genes and the resultant overexpression of ETS oncogenes alone may not be sufficient for the malignant transformation, which may require additional genetic/molecular lesions. In concordance with this concept, PCa specimens containing the TMPRSS2-ERG rearrangement were consistently reported to be concurrent with loss of the tumor suppressor PTEN [111-113], and importantly it was further demonstrated that these two somatic alterations may cooperate to promote PCa tumorigenesis using two independent transgenic mice models[111,112]. A synergy of ERG overexpression with AR signaling in transformation of primary prostate cells was also identified [110]. Taken these findings together, it is plausible that AR-induced recurrent ETS gene fusions may represent an early crucial genetic lesion which, in collaboration with other genetic/ molecular alterations, drive the whole oncogenic process of PCa.

The fact that $\mathrm{AR}$ is essential in both the formation and overexpression of the recurrent oncogenic TMPRSS2-ERG/ETV1 fusion genes in PCa is prominent and significant, as it epitomizes the critical role that AR signaling plays in the oncogenesis of $\mathrm{PCa}$, and reveals that this ARinduced somatic alteration may function as a common and important mechanism

\section{Conclusion and Future Directions}

Combining the established knowledge and the novel findings reviewed in this paper, it is evident that AR signaling is much more complicated than previously envisioned and that its role in PCa may have been significantly underappreciated. As has been illustrated, AR signaling is essentially composed of a complex regulatory network that involves DNA elements (canonical and noncanonical AREs), epigenetic factors (histone code, most notably H3K4me1/me2), and collaborating protein factors (coactivators, corepressors, and crosstalking proteins from other pathways), which are hierarchically organized and dynamically regulated. Deregulation of AR signaling is, as has also been demonstrated, deeply rooted in most, if not all, processes in the pathophysiology of PCa: before and after oncogenesis, during progression into more advanced PCa tumors, and through ADT-induced adaptation into CRPC. A better understanding of the genetic and molecular details of AR signaling pathway is highly ideal for an improved therapeutic prevention, diagnosis, treatment and prognosis of this common and deadly disease.

With this appreciation in mind, several crucial future directions should be considered. First, a thorough understanding of the genetic and molecular details of the AR signaling pathway is highly required. This may include comparative studies on the histone code, AR cistromes and the expression profiles in tissues/tumors under different pathological stages (such as normal, prostatic intraepithelial neoplasia, local, metastatic, and castration-resistant $\mathrm{PCa}$ ), and from different prostatic tumor tissues (e.g. stromal VS tumoric), identification of disease stage/ cell lineage-specific AR target genes, and search for protein cofactors that play significant roles in modulating AR transcription activity. These studies are expected to provide the framework of and pave the path for utilizing the knowledge for an improved management of the disease. Second, a better profiling and a systematic evaluation of germline and somatic, genetic, epigenetic and molecular alterations within the general AR signaling pathway that are associated to each individual disease stage is highly wanted. This will facilitate identification of individuals with higher risks for developing PCa or progressing into a metastatic and more deadly disease, or with worse prognosis for a given AR-targeting therapy. Finally, development and improvement of novel or available strategies by taking advantage of this increasing knowledge is highly needed. This may include developing new AR blocking therapies against novel therapeutic targets, and improving available clinical regimens by implementing personalized medicine, i.e. by identifying PCa patients who are expected to benefit the most.

\section{References}

1. Huggins C, Stevens RE, Hodges CV (1941) Studies on prostatic cancer II: the effects of castration on advanced carcinoma of the prostate gland. Archives of Surgery 43: 209-223. 
Citation: Feng J, Zheng SL, Liu W, Isaacs WB, Xu J (2011) Androgen Receptor Signaling in Prostate Cancer: New Twists for an Old Pathway. J Steroids Hormon Sci S2:001. doi:10.4172/2157-7536.S2-001

Page 5 of 7

2. American Cancer Society 2011. (http://www.cancer.org).

3. Isaacs JT, Coffey DS (1981) Adaptation versus selection as the mechanism responsible for the relapse of prostatic cancer to androgen ablation therapy as studied in the Dunning R-3327-H adenocarcinoma. Cancer Res 41: 5070-5075.

4. Collins AT, Berry PA, Hyde C, Stower MJ, Maitland NJ (2005) Prospective identification of tumorigenic prostate cancer stem cells. Cancer Res 65: 1094610951.

5. Kelly WK, Scher HI (1993) Prostate specific antigen decline after antiandrogen withdrawal: the flutamide withdrawal syndrome. J Urol 149: 607-609.

6. Attard G, Reid AH, A'Hern R, Parker C, Oommen NB, et al. (2009) Selective inhibition of CYP17 with abiraterone acetate is highly active in the treatment of castration-resistant prostate cancer. J Clin Oncol 27: 3742-3748.

7. Attard G, Reid AH, Olmos D, de Bono JS (2009) Antitumor activity with CYP17 blockade indicates that castration-resistant prostate cancer frequently remains hormone driven. Cancer Res 69: 4937-4940.

8. Tran C, Ouk S, Clegg NJ, Chen Y, Watson PA, et al. (2009) Development of a second-generation antiandrogen for treatment of advanced prostate cancer. Science 324: 787-790.

9. Holzbeierlein J, Lal P, LaTulippe E, Smith A, Satagopan J, et al. (2004) Gene expression analysis of human prostate carcinoma during hormonal therapy identifies androgen-responsive genes and mechanisms of therapy resistance. Am J Pathol 164: 217-227.

10. Yuan X, Li T, Wang H, Zhang T, Barua M, et al. (2006) Androgen receptor remains critical for cell-cycle progression in androgen-independent CWR22 prostate cancer cells. Am J Pathol 169: 682-696.

11. Chen CD, Welsbie DS, Tran C, Baek SH, Chen R, et al. (2004) Molecular determinants of resistance to antiandrogen therapy. Nat Med 10: 33-39.

12. Yuan X, Balk SP (2009) Mechanisms mediating androgen receptor reactivation after castration. Urol Oncol 27: 36-41.

13. Attard G, Richards J, de Bono JS (2011) New strategies in metastatic prostate cancer: targeting the androgen receptor signaling pathway. Clin Cancer Res 17: $1649-1657$

14. Knudsen KE, Penning TM (2010) Partners in crime: deregulation of AR activity and androgen synthesis in prostate cancer. Trends Endocrinol Metab 21: 315324.

15. Sadar MD (2011) Small molecule inhibitors targeting the "achilles' heel" of androgen receptor activity. Cancer Res 71: 1208-1213.

16. Sharifi $N(2010)$ New agents and strategies for the hormonal treatment of castration-resistant prostate cancer. Expert Opin Investig Drugs 19: 837-846.

17. Vasaitis TS, Njar VC (2010) Novel, potent anti-androgens of therapeutic potential: recent advances and promising developments. Future Med Chem 2: 667-680.

18. Luu-The V, Belanger A, Labrie F (2008) Androgen biosynthetic pathways in the human prostate. Best Pract Res Clin Endocrinol Metab 22: 207-221.

19. Tammela T (2004) Endocrine treatment of prostate cancer. J Steroid Biochem Mol Biol 92: 287-295.

20. Vis AN, Schroder FH (2009) Key targets of hormonal treatment of prostate cancer. Part 2: the androgen receptor and 5alpha-reductase. BJU Int 104 1191-1197.

21. Nacusi LP, Tindall DJ (2011) Targeting 5a-reductase for prostate cancer prevention and treatment. Nat Rev Urol 8: 378-384

22. Roy AK, Lavrovsky Y, Song CS, Chen S, Jung MH, et al. (1999) Regulation of androgen action. Vitam Horm 55: 309-352.

23. Heinlein CA, Chang C (2002) Androgen receptor (AR) coregulators: an overview. Endocr Rev 23: 175-200.

24. Marivoet S, Van Dijck P, Verhoeven G, Heyns W (1992) Interaction of the 90$\mathrm{kDa}$ heat shock protein with native and in vitro translated androgen receptor and receptor fragments. Mol Cell Endocrinol 88: 165-174.

25. Ciocca DR, Fanelli MA, Cuello-Carrion FD, Castro GN (2010) Heat shock proteins in prostate cancer: from tumorigenesis to the clinic. Int J Hyperthermia 26: $737-747$

26. Centenera MM, Harris JM, Tilley WD, Butler LM (2008) The contribution of different androgen receptor domains to receptor dimerization and signaling Mol Endocrinol 22: 2373-2382.

27. Chmelar R, Buchanan G, Need EF, Tilley W, Greenberg NM (2007) Androgen receptor coregulators and their involvement in the development and progression of prostate cancer. Int J Cancer 120: 719-733.

28. Vis AN, Schroder FH (2009) Key targets of hormonal treatment of prostate cancer. Part 1: the androgen receptor and steroidogenic pathways. BJU Int 104: 438-448.

29. Gao X, Loggie BW, Nawaz Z (2002) The roles of sex steroid receptor coregulators in cancer. Mol Cancer 1: 7

30. Agoulnik IU, Weigel NL (2008) Androgen receptor coactivators and prostate cancer. Adv Exp Med Biol 617: 245-255

31. Burd CJ, Morey LM, Knudsen KE (2006) Androgen receptor corepressors and prostate cancer. Endocr Relat Cancer 13: 979-994.

32. Wu CT, Altuwaijri S, Ricke WA, Huang SP, Yeh S, et al. (2007) Increased prostate cell proliferation and loss of cell differentiation in mice lacking prostate epithelial androgen receptor. Proc Natl Acad Sci U S A 104: 12679-12684.

33. Niu Y, Altuwaijri S, Yeh S, Lai KP, Yu S, et al. (2008) Targeting the stromal androgen receptor in primary prostate tumors at earlier stages. Proc Natl Acad Sci U S A 105: 12188-12193.

34. Niu Y, Altuwaijri S, Lai KP, Wu CT, Ricke WA, et al. (2008) Androgen recepto is a tumor suppressor and proliferator in prostate cancer. Proc Natl Acad Sci U S A 105: 12182-12187.

35. Colombel M, Olsson CA, Ng PY, and Buttyan R (1992) Hormone-regulated apoptosis results from reentry of differentiated prostate cells onto a defective cell cycle. Cancer Res 52: 4313-4319.

36. Castoria G, D'Amato L, Ciociola A, Giovannelli P, Giraldi T, et al. (2011) Androgen-induced cell migration: role of androgen receptor/filamin A association. PLoS One 6: e17218.

37. Hornberg E, Ylitalo EB, Crnalic S, Antti H, Stattin P, et al. (2011) Expression of androgen receptor splice variants in prostate cancer bone metastases is associated with castration-resistance and short survival. PLoS One 6: e19059.

38. Heinlein CA, Chang C (2004) Androgen receptor in prostate cancer. Endocr Rev 25: 276-308.

39. Labrie F, Cusan L, Gomez JL, Martel C, Berube R, et al. (2009) Comparable amounts of sex steroids are made outside the gonads in men and women: strong lesson for hormone therapy of prostate and breast cancer. J Steroid Biochem Mol Biol 113: 52-56.

40. Sharifi N, Gulley JL, Dahut WL (2005) Androgen deprivation therapy fo prostate cancer. JAMA 294: 238-244.

41. Chen Y, Sawyers CL, Scher $\mathrm{HI}$ (2008) Targeting the androgen recepto pathway in prostate cancer. Curr Opin Pharmacol 8: 440-448.

42. de Bono JS, Logothetis CJ, Molina A, Fizazi K, North S, et al. (2011) Abiraterone and increased survival in metastatic prostate cancer. N Engl J Med 364: 1995 2005

43. Attar RM, Jure-Kunkel M, Balog A, Cvijic ME, Dell-John J, et al. (2009) Discovery of BMS-641988, a novel and potent inhibitor of androgen receptor signaling for the treatment of prostate cancer. Cancer Res 69: 6522-6530.

44. Safety Study of TAK-700 in Subjects With Prostate Cancer [Clinical Trialsgov identifier NCT00569153] US National Institutes of Health. http://clinicaltrials gov. Accessed February 9.

45. Vasaitis T, Belosay A, Schayowitz A, Khandelwal A, Chopra P, et al. (2008) Androgen receptor inactivation contributes to antitumor efficacy of 17 alpha\} hydroxylase/17,20-lyase inhibitor 3beta-hydroxy-17-(1H-benzimidazole-1-yl) androsta-5,16-diene in prostate cancer. Mol Cancer Ther 7: 2348-2357.

46. Wang Q, Li W, Liu XS, Carroll JS, Janne OA, et al. (2007) A hierarchical network of transcription factors governs androgen receptor-dependent prostate cancer growth. Mol Cell 27: 380-392.

47. Wang Q, Li W, Zhang Y, Yuan X, Xu K, et al. (2009) Androgen recepto regulates a distinct transcription program in androgen-independent prostate cancer. Cell 138: 245-256.

48. Yu J, Mani RS, Cao Q, Brenner CJ, Cao X, et al. (2010) An integrated network of androgen receptor, polycomb, and TMPRSS2-ERG gene fusions in prostate cancer progression. Cancer Cell 17: 443-454. 
Citation: Feng J, Zheng SL, Liu W, Isaacs WB, Xu J (2011) Androgen Receptor Signaling in Prostate Cancer: New Twists for an Old Pathway. J Steroids Hormon Sci S2:001. doi:10.4172/2157-7536.S2-001

49. Lin B, Wang J, Hong X, Yan X, Hwang D, et al. (2009) Integrated expression profiling and ChIP-seq analyses of the growth inhibition response program of the androgen receptor. PLoS One 4: e6589.

50. Takayama K, Kaneshiro K, Tsutsumi S, Horie-Inoue K, Ikeda K, et al. (2007) Identification of novel androgen response genes in prostate cancer cells by coupling chromatin immunoprecipitation and genomic microarray analysis. Oncogene 26: 4453-4463.

51. Lupien M, Eeckhoute J, Meyer CA, Wang Q, Zhang Y, et al. (2008) FoxA1 translates epigenetic signatures into enhancer-driven lineage-specific transcription. Cell 132: 958-970

52. Wang D, Garcia-Bassets I, Benner C, Li W, Su X, et al. (2011) Reprogramming transcription by distinct classes of enhancers functionally defined by eRNA. Nature 474: 390-394.

53. Imperato-McGinley J, Zhu YS (2002) Androgens and male physiology the syndrome of 5alpha-reductase-2 deficiency. Mol Cell Endocrinol 198: 51-59.

54. Zhu YS, Sun GH (2005) 5a-Reductase Isozymes in the Prostate. J Med Sci 25 $1-12$.

55. Griffin JE (1992) Androgen resistance--the clinical and molecular spectrum. N Engl J Med 326: 611-618.

56. Caskey CT, Pizzuti A, Fu YH, Fenwick RG, Nelson DL (1992) Triplet repea mutations in human disease. Science 256: 784-789.

57. Noble RL (1977) Sex steroids as a cause of adenocarcinoma of the dorsa prostate in $\mathrm{Nb}$ rats, and their influence on the growth of transplants. Oncology 34: 138-141.

58. Pollard M (1998) Lobund-Wistar rat model of prostate cancer in man. Prostate 37: $1-4$.

59. Barrett-Connor E, Garland C, McPhillips JB, Khaw KT, Wingard DL (1990) A prospective, population-based study of androstenedione, estrogens, and prostatic cancer. Cancer Res 50: 169-173.

60. Gann PH, Hennekens CH, Ma J, Longcope C, Stampfer MJ (1996) Prospective study of sex hormone levels and risk of prostate cancer. J Natl Cancer Inst 88: 1118-1126.

61. Parsons JK, Carter HB, Platz EA, Wright EJ, Landis P, et al. (2005) Serum testosterone and the risk of prostate cancer: potential implications for testosterone therapy. Cancer Epidemiol Biomarkers Prev 14: 2257-2260.

62. Dorgan JF, Albanes D, Virtamo J, Heinonen OP, Chandler DW, et al. (1998) Relationships of serum androgens and estrogens to prostate cancer risk: results from a prospective study in Finland. Cancer Epidemiol Biomarkers Prev 7: 1069-1074.

63. Heikkila R, Aho K, Heliovaara M, Hakama M, Marniemi J, et al. (1999) Serum testosterone and sex hormone-binding globulin concentrations and the risk of prostate carcinoma: a longitudinal study. Cancer 86: 312-315

64. Mohr BA, Feldman HA, Kalish LA, Longcope C, and McKinlay JB (2001) Are serum hormones associated with the risk of prostate cancer? Prospective results from the Massachusetts Male Aging Study. Urology 57: 930-935.

65. Platz EA, Leitzmann MF, Rifai N, Kantoff PW, Chen YC, et al. (2005) Sex steroid hormones and the androgen receptor gene $C A G$ repeat and subsequent risk of prostate cancer in the prostate-specific antigen era. Cancer Epidemio Biomarkers Prev 14: 1262-1269.

66. Travis RC, Key TJ, Allen NE, Appleby PN, Roddam AW, et al. (2007) Serum androgens and prostate cancer among 643 cases and 643 controls in the European Prospective Investigation into Cancer and Nutrition. Int $\mathrm{J}$ Cancer 121: 1331-1338.

67. Eaton NE, Reeves GK, Appleby PN, Key TJ (1999) Endogenous sex hormones and prostate cancer: a quantitative review of prospective studies. $\mathrm{Br} \mathrm{J}$ Cancer 80: $930-934$

68. Roddam AW, Allen NE, Appleby P, and Key TJ (2008) Endogenous sex hormones and prostate cancer: a collaborative analysis of 18 prospective studies. J Natl Cancer Inst 100: 170-183.

69. Gu M, Dong X, Zhang X, Niu W (2011) The CAG repeat polymorphism of androgen receptor gene and prostate cancer: a meta-analysis. Mol Biol Rep.

70. Nicolaiew N, Cancel-Tassin G, Azzouzi AR, Grand BL, Mangin P, et al. (2009) Association between estrogen and androgen receptor genes and prostate cancer risk. Eur J Endocrinol 160: 101-106.
71. Price DK, Chau CH, Till C, Goodman PJ, Baum CE, et al. (2010) Androgen receptor CAG repeat length and association with prostate cancer risk: results from the prostate cancer prevention trial. J Urol 184: 2297-2302.

72. Lindstrom S, Ma J, Altshuler D, Giovannucci E, Riboli E, et al. (2010) A large study of androgen receptor germline variants and their relation to sex hormone levels and prostate cancer risk. Results from the National Cancer Institute Breast and Prostate Cancer Cohort Consortium. J Clin Endocrinol Metab 95 121-127.

73. Lichtenstein P, Holm NV, Verkasalo PK, Iliadou A, Kaprio J, et al. (2000) Environmental and heritable factors in the causation of cancer--analyses of cohorts of twins from Sweden, Denmark, and Finland. N Engl J Med 343: 78 85.

74. Gudmundsson J, Sulem P, Manolescu A, Amundadottir LT, Gudbjartsson D, et al. (2007) Genome-wide association study identifies a second prostate cancer susceptibility variant at 8q24. Nat Genet 39: 631-637.

75. Yeager M, Orr N, Hayes RB, Jacobs KB, Kraft P, et al. (2007) Genome-wide association study of prostate cancer identifies a second risk locus at 8q24. Nat Genet 39: 645-649

76. Gudmundsson J, Sulem P, Steinthorsdottir V, Bergthorsson JT, Thorleifsson G, et al. (2007) Two variants on chromosome 17 confer prostate cancer risk, and the one in TCF2 protects against type 2 diabetes. Nat Genet 39: 977-983.

77. Duggan D, Zheng SL, Knowlton M, Benitez D, Dimitrov L, et al. (2007) Two genome-wide association studies of aggressive prostate cancer implicate putative prostate tumor suppressor gene DAB2IP. J Natl Cancer Inst 99: 1836 1844

78. Thomas G, Jacobs KB, Yeager M, Kraft P, Wacholder S, et al. (2008) Multiple loci identified in a genome-wide association study of prostate cancer. Nat Genet 40: 310-315.

79. Gudmundsson J, Sulem P, Rafnar T, Bergthorsson JT, Manolescu A, et al (2008) Common sequence variants on 2 p15 and Xp11.22 confer susceptibility to prostate cancer. Nat Genet 40: 281-283.

80. Eeles RA, Kote-Jarai Z, Giles GG, Olama AA, Guy M, et al. (2008) Multiple newly identified loci associated with prostate cancer susceptibility. Nat Genet 40: 316-321.

81. Sun J, Zheng SL, Wiklund F, Isaacs SD, Purcell LD, et al. (2008) Evidence for two independent prostate cancer risk-associated loci in the HNF1B gene at 17q12. Nat Genet 40: 1153-1155

82. Yeager M, Chatterjee N, Ciampa J, Jacobs KB, Gonzalez-Bosquet J, et al. (2009) Identification of a new prostate cancer susceptibility locus on chromosome 8q24. Nat Genet 41: 1055-1057.

83. Gudmundsson J, Sulem P, Gudbjartsson DF, Blondal T, Gylfason A, et al. (2009) Genome-wide association and replication studies identify four variants associated with prostate cancer susceptibility. Nat Genet 41: 1122-1126.

84. Eeles RA, Kote-Jarai Z, Al Olama AA, Giles GG, Guy M, et al. (2009) Identification of seven new prostate cancer susceptibility loci through a genome-wide association study. Nat Genet 41: 1116-1121

85. Amundadottir LT, Sulem P, Gudmundsson J, Helgason A, Baker A, et al. (2006) A common variant associated with prostate cancer in European and African populations. Nat Genet 38: 652-658.

86. Kote-Jarai Z, Easton DF, Stanford JL, Ostrander EA, Schleutker J, et al. (2008) Multiple novel prostate cancer predisposition loci confirmed by an international study: the PRACTICAL Consortium. Cancer Epidemiol Biomarkers Prev 17 2052-2061.

87. Chang BL, Spangler E, Gallagher S, Haiman CA, Henderson B, et al. (2011) Validation of genome-wide prostate cancer associations in men of African descent. Cancer Epidemiol Biomarkers Prev 20: 23-32.

88. Zheng SL, Hsing AW, Sun J, Chu LW, Yu K, et al. (2010) Association of 17 prostate cancer susceptibility loci with prostate cancer risk in Chinese men. Prostate 70: 425-432.

89. Yamada H, Penney KL, Takahashi H, Katoh T, Yamano Y, et al. (2009) Replication of prostate cancer risk loci in a Japanese case-control association study. J Natl Cancer Inst 101: 1330-1336.

90. Lu Y, Zhang Z, Yu H, Zheng SL, Isaacs WB, et al. (2011) Functional annotation of risk loci identified through genome-wide association studies for prostate cancer. Prostate 71: 955-963. 
Citation: Feng J, Zheng SL, Liu W, Isaacs WB, Xu J (2011) Androgen Receptor Signaling in Prostate Cancer: New Twists for an Old Pathway. J Steroids Hormon Sci S2:001. doi:10.4172/2157-7536.S2-001

91. Lu Y, Sun J, Kader AK, Kim ST, Kim JW, et al. (2011) Association of prostate cancer risk with SNPs in regions containing androgen receptor binding sites captured by ChIP-on-chip analyses. Prostate (in press)

92. Thompson IM, Goodman PJ, Tangen CM, Lucia MS, Miller GJ, et al. (2003) The influence of finasteride on the development of prostate cancer. $\mathrm{N}$ Engl $\mathrm{J}$ Med 349: 215-224.

93. Andriole GL, Bostwick DG, Brawley OW, Gomella LG, Marberger M, et al. (2010) Effect of dutasteride on the risk of prostate cancer. N Engl J Med 362 1192-1202.

94. Tomlins SA, Rhodes DR, Perner S, Dhanasekaran SM, Mehra R, et al. (2005) Recurrent fusion of TMPRSS2 and ETS transcription factor genes in prostate cancer. Science 310: 644-648.

95. Mehra R, Tomlins SA, Shen R, Nadeem O, Wang L, et al. (2007) Comprehensive assessment of TMPRSS2 and ETS family gene aberrations in clinically localized prostate cancer. Mod Pathol 20: 538-544.

96. Tu JJ, Rohan S, Kao J, Kitabayashi N, Mathew S, et al. (2007) Gene fusions between TMPRSS2 and ETS family genes in prostate cancer: frequency and transcript variant analysis by RT-PCR and FISH on paraffin-embedded tissues. Mod Pathol 20: 921-928.

97. Han B, Mehra R, Dhanasekaran SM, Yu J, Menon A, et al. (2008) A fluorescence in situ hybridization screen for E26 transformation-specific aberrations: identification of DDX5-ETV4 fusion protein in prostate cancer. Cancer Res 68: 7629-7637.

98. Helgeson BE, Tomlins SA, Shah N, Laxman B, Cao Q, et al. (2008) Characterization of TMPRSS2:ETV5 and SLC45A3:ETV5 gene fusions in prostate cancer. Cancer Res 68: 73-80.

99. Tomlins SA, Mehra R, Rhodes DR, Smith LR, Roulston D, et al. (2006) TMPRSS2:ETV4 gene fusions define a third molecular subtype of prostate cancer. Cancer Res 66: 3396-3400.

100. Hermans KG, Bressers AA, van der Korput HA, Dits NF, Jenster G, et al. (2008) Two unique novel prostate-specific and androgen-regulated fusion partners of ETV4 in prostate cancer. Cancer Res 68: 3094-3098.

101. Hermans KG, van Marion R, van Dekken H, Jenster G, van Weerden WM, et al. (2006) TMPRSS2:ERG fusion by translocation or interstitial deletion is highly relevant in androgen-dependent prostate cancer, but is bypassed in late-stage androgen receptor-negative prostate cancer. Cancer Res 66: 10658-10663.
102. Perner S, Demichelis F, Beroukhim R, Schmidt FH, Mosquera JM, et al. (2006) TMPRSS2:ERG fusion-associated deletions provide insight into the heterogeneity of prostate cancer. Cancer Res 66: 8337-8341.

103. Wang J, Cai Y, Ren C, and Ittmann M (2006) Expression of variant TMPRSS2 ERG fusion messenger RNAs is associated with aggressive prostate cancer. Cancer Res 66: 8347-8351.

104. Lin C, Yang L, Tanasa B, Hutt K, Ju BG, et al. (2009) Nuclear receptor-induced chromosomal proximity and DNA breaks underlie specific translocations in cancer. Cell 139: 1069-1083.

105. Haffner MC, Aryee MJ, Toubaji A, Esopi DM, Albadine R, et al. Androgeninduced TOP2B-mediated double-strand breaks and prostate cancer gene rearrangements. Nat Genet 42: 668-675.

106. Mosquera JM, Perner S, Genega EM, Sanda M, Hofer MD, et al. (2008) Characterization of TMPRSS2-ERG fusion high-grade prostatic intraepithelial neoplasia and potential clinical implications. Clin Cancer Res 14: 3380-3385.

107. Cerveira N, Ribeiro FR, Peixoto A, Costa V, Henrique R, et al. (2006) TMPRSS2-ERG gene fusion causing ERG overexpression precedes chromosome copy number changes in prostate carcinomas and paired HGPIN lesions. Neoplasia 8: 826-832.

108. Tomlins SA, Laxman B, Dhanasekaran SM, Helgeson BE, Cao X, et al. (2007) Distinct classes of chromosomal rearrangements create oncogenic ETS gene fusions in prostate cancer. Nature 448: 595-599.

109. Tomlins SA, Laxman B, Varambally S, Cao X, Yu J, et al. (2008) Role of the TMPRSS2-ERG gene fusion in prostate cancer. Neoplasia 10: 177-188.

110.Zong Y, Xin L, Goldstein AS, Lawson DA, Teitell MA, et al. (2009) ETS family transcription factors collaborate with alternative signaling pathways to induce carcinoma from adult murine prostate cells. Proc Natl Acad Sci U S A 106 12465-12470

111. King JC, Xu J, Wongvipat J, Hieronymus H, Carver BS, et al. (2009) Cooperativity of TMPRSS2-ERG with PI3-kinase pathway activation in prostate oncogenesis. Nat Genet 41: 524-526.

112. Carver BS, Tran J, Gopalan A, Chen Z, Shaikh S, et al. (2009) Aberrant ERG expression cooperates with loss of PTEN to promote cancer progression in the prostate. Nat Genet 41: 619-624.

113. Bismar TA, Yoshimoto M, Vollmer RT, Duan Q, Firszt M, et al. PTEN genomic deletion is an early event associated with ERG gene rearrangements in prostate cancer. BJU Int 107: 477-485.
This article was originally published in a special issue, Androgen Receptors handled by Editor(s). Dr. Rebecca L Cunningham, University of North Texas Health Science Center, USA; Dr. Ze-hua Liu, Osaka City University, Japan 